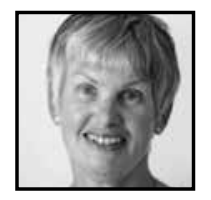

\title{
How We Learn Together: Young Children (and Their Mums) Using Animal Metaphors and Imagery to Understand and Manage Learning
}

Helen Jelfs, University of Bristol

\begin{abstract}
In this paper I discuss the "Language for Learning" project which used animal metaphors and imagery in an early childhood education setting as a way of enabling children to understand and manage their own learning. The concept of "learning power" was communicated through metaphor and the use of image, movement, and music, which in turn led to the development of a rich and local language for learning. An unexpected outcome of this project was its capacity to generate positive learning experiences for young children and their parents, and to generate personal and social transformation within the wider community.
\end{abstract}

\section{Introduction}

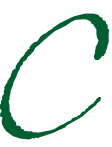

hildren growing up in disadvantaged households in the United Kingdom (UK) achieve significantly lower levels of educational success than children from more affluent families. The gap in skills, abilities, attitudes, values, and dispositions emerges early and along many dimensions, and widens during the course of pre-, primary, and secondary schooling (Feinstein, 2003; Goodman, Sibieta, \& Washbrook, 2009). There is clear evidence that these educational deficits are apparent early in children's lives and even before entry into school (Goodman \& Gregg, 2010). Indeed, the gap between children from poorer backgrounds and those from better-off backgrounds widens through the school years, especially during the primary school years. Not only are there big differences in cognitive development, but also in their social 
and emotional development. Goodman and Gregg (2010) also draw attention to significant differences in what they term the "early childhood caring environments," especially with respect to family interactions such as mother-child closeness and the home learning environment. They suggest that, "differences in the home learning environment, particularly at the age of three, have an important role to play in explaining why children from poorer backgrounds have lower test scores than children from better-off families" ( p. 6). They also propose that, "many aspects of the early childhood caring environment do have a positive effect on children's social and emotional development, meaning that policies aimed at improving health, parenting skills and the home learning environment could still be very important" (p. 6).

The Language for Learning project was based in a specialist nursery school in a socially deprived area of a city in the southwest of the UK. It was an initiative designed to raise aspirations within the local community by offering a tangible focus on learning and achievement for children and their parents. Nursery schools provide early childhood education for children aged between three and five years old; the Early Years Foundation Stage (EYFS) is the statutory framework that governs the kind of educational provision young children should experience in order to learn and develop well at this age (Department for Education, 2013). The Language for Learning project refers to the seven dimensions of learning of "learning power" (Deakin Crick, 2006; Deakin Crick, Broadfoot, \& Claxton, 2004; Deakin Crick, McCombs, Haddon, Broadfoot, \& Tew, 2007) together with the animal characters that have been developed for each of the dimensions. These are:

- Changing and Learning (chameleon) - A sense of changing and growing as a learner

- Meaning Making (spider) - Making learning personally meaningful by making connections between what is learnt and what is already known

- Curiosity (cat) - An inclination to ask questions, to get below the surface of things and come to own conclusions

- Creativity (unicorn) - Risk taking, playfulness, lateral thinking and using imagination and intuition to learn

- Learning relationships (bees) - The ability to learn with and from other people and to learn on my own

- Resilience (snail) - The tenacity to persist in the face of confusion, not knowing and failure 
- Strategic Awareness (owl) - Being aware and actively managing my own feelings, processes, and strategies

The use of animal metaphors and imagery to communicate the concept of "learning power" proved to be a powerful way of enabling young children to understand and manage their own learning, as well as re-engaging their parents in learning. The ideas were introduced to the children through the use of images, movement, dressing-up clothes, puppets, stories, and songs, and over time this approach became embedded in the school and its curriculum.

Supported by the school, a group of children and parents worked together to design a large mural depicting the seven animals, which was then painted on a shop wall in the community. The parents subsequently wrote a booklet in which they shared with other parents how to help their child learn. Doing this work enabled mums to reflect on their own experiences of school, and in some cases to confront and overcome their own profound fear of school (particularly the secondary school they went to when they were young). Other local primary schools also began adopting the ideas and designed their own murals.

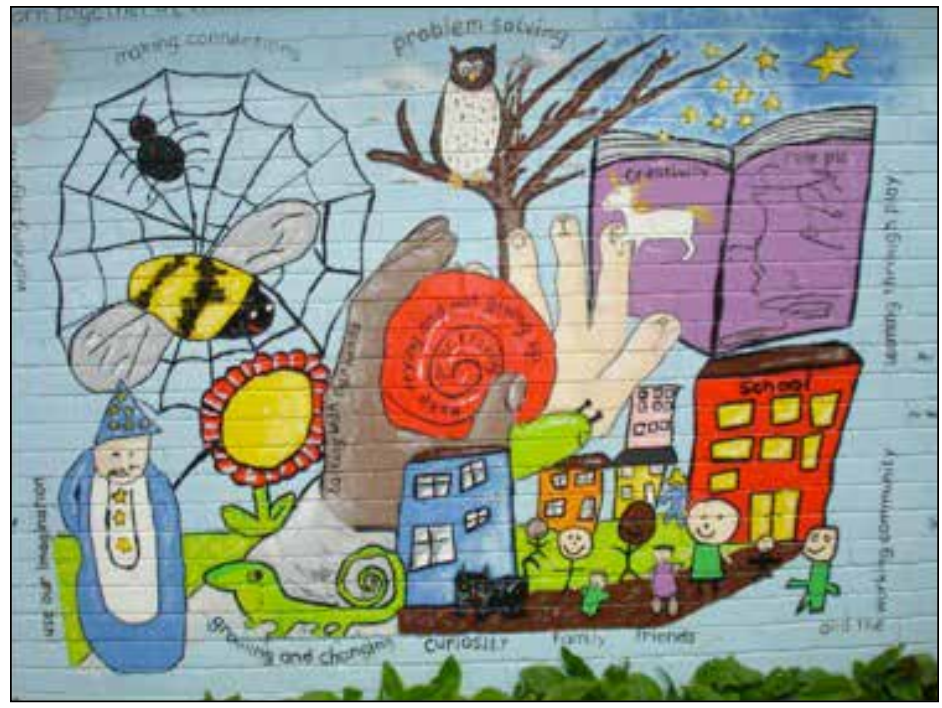

Fig. 1: The community mural, depicting seven dimensions of learning power 


\section{The Ecology of Learning}

It is now widely agreed that schools in the UK need to develop a coherent and consistent approach to learning (Hopkins, 2000; Watkins, 2001, 2006). This involves making learning, as a process and participative experience, explicit whilst also valuing the learner's sense of his or her own identity as a learner (Deakin Crick \& Wilson, 2005). Essentially, the classroom culture needs to promote thinking and learning, and be a place where teachers model their own curiosity and desire to learn (Watkins, 2001). Children and young people should talk about and reflect on their learning, and learning skills and dispositions should feature in learning intentions. Schools are also expected to make thinking visible by displaying thinking tools, encouraging collaboration and dialogue, and valuing the students' own thoughts and questions (de A'Echevarria, 2008). Such an approach requires children and young people to not only talk about what they have learned about a particular subject, but also to talk about the thinking and learning process itself. Encouraging them to think about how their learning relates to other areas of the curriculum and in everyday life is also to be encouraged, and the teacher's thoughtful questioning supports metacognitive thinking of this kind.

Schools that promote effective learning emphasise intrinsic motivation, social relationships for learning, and an overall learning culture. They are learning organisations, making many connections within and beyond their boundaries. "Learningenriched" schools display more sense of purpose (i.e. learning), and are less routinised than the learning impoverished school. Teachers see peers as a resource, and continue to learn: new teaching ideas come from colleagues and their own creative solutions. The greater teachers' opportunities for learning, the more their students tend to learn: pupils achieve better in learning-enriched schools. (Watkins, Carnell, Lodge, Wagner, \& Whalley, 2002, p. 6)

Powerful learning (Hopkins, 2000) is another way to speak of this approach; that is the development of a range of learning strategies, or meta-cognitive skills that enable students to:

integrate prior and new knowledge; acquire and use a range of learning skills; solve problems individually and in groups; think carefully about their successes and failures; evaluate conflicting evidence and to think critically; and accept that learning involves uncertainty and difficulty. (p. 140)

Skills such as these enable learners to manage their own learning so that both their learning capability and self-esteem is enhanced. 
Learning power (Deakin Crick, 2006; Deakin Crick et al., 2004) is one approach to learning that seeks to address the kind of issues raised above. It is a way of describing the complex mix of dispositions, lived experiences, social relations, values, and attitudes that combine to influence how an individual engages with particular learning opportunities.

Early on in the development of learning power, it became apparent that "personifying" each of the learning dimensions with an animal character proved to be a creative and captivating way of engaging children in talking about learning in general and their own learning in particular (see Millington, D. in Deakin Crick 2006). Indeed, as the concept of learning power was rolled out in other learning communities, it became apparent that ownership of the language for learning vocabulary became specific to each learning situation. For example, work in this area with Australian students in an Indigenous Learning Centre in New South Wales demonstrated the importance of reworking the animal characters to reflect native Australian animals as icons for learning power, rather than accept the Western characterization of the learning dimensions (Deakin Crick \& Grushka, 2009).

A key facet of the development of the seven dimensions of learning power has been this rich metaphorical aspect. Discussing the importance of metaphor, Lakoff and Johnson (2003) state that our conceptual system - in terms of how we think and act-is essentially metaphorical in nature. Furthermore, they suggest that thinking, experiencing, and doing is very much to do with metaphor. What perhaps is particularly relevant here in relation to the language for learning is that using objects (i.e., the animals) to understand experiences provides the opportunity to "treat them as discrete entities" which then allows us to "refer to them, categorize them, group them, and quantify them - and by this means, reason about them" (Lakoff \& Johnson, 2003, p. 25). The animal characterization has created the possibility of shared metaphors that not only hold key concepts about the process of learning, but which also make it possible for the learner to identify with. Metaphor and image together create the possibility of rich connections between the learner and the learning experience, as well as the possibility of more effectively scaffolding learning (Deakin Crick \& Grushka, 2009).

\section{Community-Based Research}

The extent to which the language for learning had been developed in this particular community was only bought to the attention of researchers some years after 
its development. Whilst what the school had done could be described as a piece of community-based research, it was only later that the head teacher invited me into the school to see what had been achieved and the impact it had had within the school and wider community. Community-based research has been described by Hills and Mullett (2000) as:

...a collaboration between community groups and researchers for the purpose of creating new knowledge or understanding about a practical community issue in order to bring about change. The issue is generated by the community and community members participate in all aspects of the research process. Community-based research therefore is collaborative, participatory, empowering, systematic and transformative. (p. 2)

So, although not designed as a piece of community-based research, this inquiry does reflect the principles on which such research proceeds because it

- creates new knowledge upon which to base practice

- provide[s] information which is in some other way directly useful to the community in which it is initiated

- values the work and perspectives of each participant

- deals with a problem or practical issue which has been identified by the community as being important to the life/health of that community

- allows people to develop new ways of thinking, behaving and practising

- makes a lasting contribution to the community (Hills \& Mullett, 2000, p. 3)

My research included in-depth interviews with the head teacher, the project leader, two nursery assistants, and one of the school cleaners who was also a local youth worker. I also interviewed the art teacher who had helped to produce the mural and four mothers, two who had been involved in creating the mural and two whose children were then attending the nursery. I spent a morning in a nursery classroom in order to experience firsthand how children were using the learning language, and I also joined one of the parent singing sessions. To summarize then, the research data included interviews, field notes and observations, photographs and artefacts. As well as finding out about the development of the project, I was particularly interested to hear what it was about the project that caught the interest and imagination of children and parents; its significance for the school and community and what aspirations there were for its ongoing development. 


\section{The Language for Learning Story}

The original research (Deakin Crick et al., 2004) which informs the theoretical perspectives on effective learning and learners adopted in the Language for Learning project sought to define a good learner and to devise an assessment instrument (ELLI the Effective Lifelong Learning inventory) which could be used to assess an individual's capacity for learning at any time in a given setting. It also explored how such information might be used to support an individual or group's learning energy. At the same time, work was undertaken with a small number of schools and teachers to see how useful the concepts might be in practice.

\section{Embedding the Language}

The Language for Learning project exemplifies what happened when one inspired headteacher sought to adapt the ideas for use within her early years setting. Following a successful pilot by one of its teachers, the Language for Learning project was rolled out across the nursery school. A whole-school approach and ongoing professional development work with the staff in how to use the language was crucial to its success, and it gradually became embedded across the curriculum in every class. Learning as they went along, staff captured words and phrases they heard children use and developed language mind maps for each of the animals/learning dimensions. Figure $2 \mathrm{dem}$ onstrates the mind map generated for Changing \& Learning.

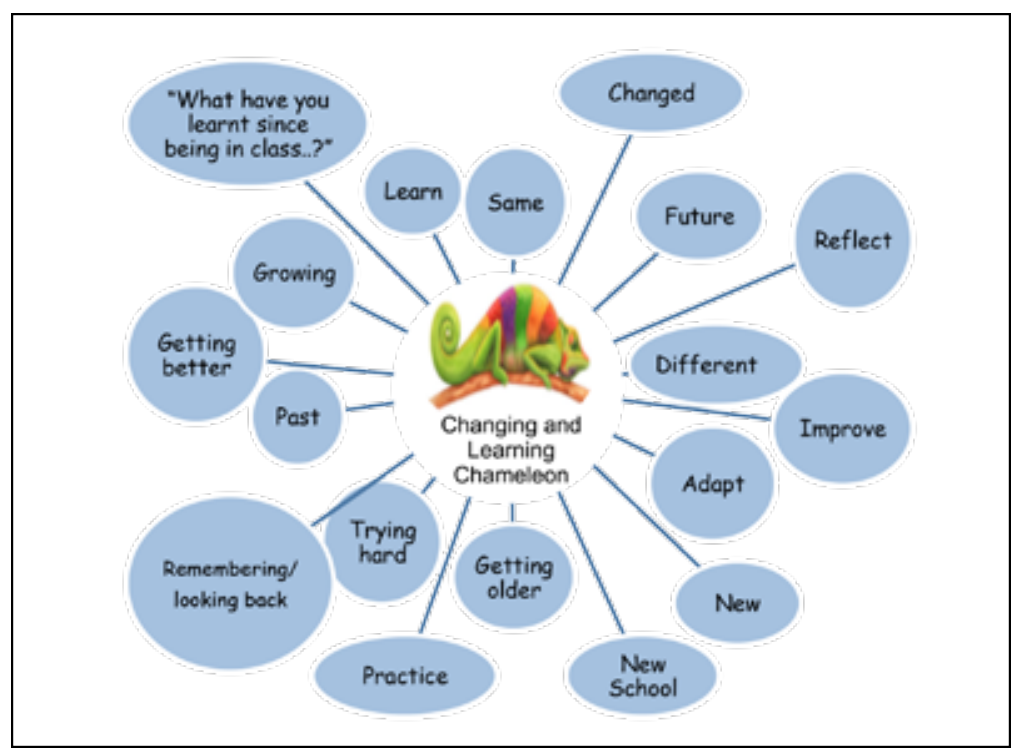

Fig. 2: Mind map for changing and learning 
The development and use of this community-generated language reinforced the community generation and ownership of the Language for Learning project. A number of strategies were used to help parents understand the Language for Learning project and to support them in using it with their children. These included a presentation to new parents, information on notice boards and in letters, and songs written based on each of the animals. Parents were regularly invited to join in class singing sessions where they become familiar with the songs and the ideas they represented. One of the songs is included here.

Making Connections (To the tune of Incy Wincy Spider)

Web weaving spider

had a silky thread.

Connected all the thoughts

to make ideas in his head.

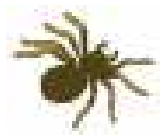

Another way in which the learning language was reinforced was the use of stickers that explained how children had used or applied their learning language during the day. One of the stickers is shown here.

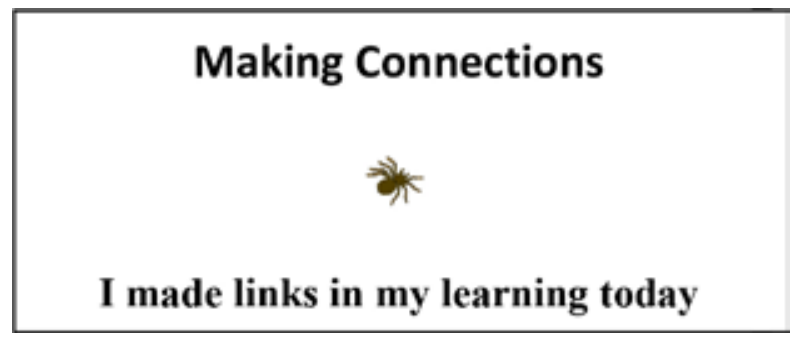

Fig. 3: Example of sticker

Although all the learning dimensions were used throughout the year, there was a progressive focus on each of the animals. Careful planning identified how the animals linked to the focus of class activities, and tried-and-tested activities plus new ones were included.

\section{Making the Mural}

Thrilled by the impact the use of the learning language was having on the children's learning, especially their language development and their ability to reflect and talk about their experiences, the school decided to take things further by creating a mural. 
Entitled "How we learn" and located in the heart of the community where people would walk past it every day, it would be a reminder of the learning taking place in the nursery school. An art teacher from the nearby secondary school was enlisted to help facilitate it. Being involved in such a venture was a considerable challenge for those parents who agreed to be involved. But over time they came to understand more about how their children were approaching learning and how they could develop in this respect, too.

Eventually, a suitable location for the mural - the end wall of a row of shops in the heart of the community-was identified. The site was very run-down and unsightly with beer cans, broken glass, and syringes, but in time the site was cleared, paving slabs were put down and the school caretaker painted the wall white ready to be painted on. Everyone was concerned about how safe the mural would be but the school cleaner and local youth worker encouraged them to trust that people would value something that had been created by the families of the community.

There was considerable local interest in what was happening as school staff, parents, and children gathered one summer's evening to begin making the mural. Local adults and young people wanted to know what was going on and how they could help. In the end, local residents, family and friends, together with a number of young people, worked together to get the outline onto the wall. The next day the painting of the mural started. To begin with, the parents were unsure about the children being involved in painting the mural because they thought they were too young and would mess it up, but the school staff reminded them that it was their mural as well. Anti-graffiti paint was put over the top, but the mural has not been defaced. The local press were invited and the community proudly celebrated what had been achieved.

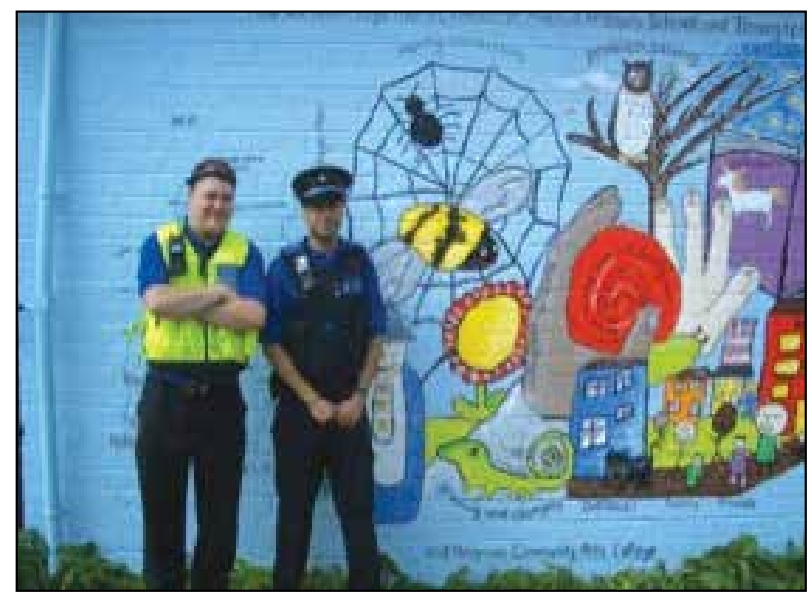

Fig. 4: Two community policy officers standing in front of the children's mural 


\section{Creating the Booklet}

Everyone felt that the mural was a great success and were really proud of what had been achieved, but it was decided that some explanation was needed and so the muralmaking team set about creating a booklet to explain the mural. The parents decided to talk about the barriers to learning because they realized that through this process they had changed, compared to what they were like when they first came. Once completed, the booklet was distributed to parents within their own nursery and was also subsequently distributed in other local schools. Affirmation of the contribution the Language for Learning project made to children's learning came when the nursery school had a successful school inspection soon after (Curtis, 2008). The inspector was really impressed with what he saw and heard, and recounted one particular encounter in which he was particularly impressed by the children's use of the language. The scenario went like this:

Masie, one of the children, was in the role-play area banging two bricks together. He went over to her and said, "What are you doing?" She said, I am learning like the spider and making connections in my learning because Miss Jenny read us the story of the elves and the shoe maker yesterday and today I have remembered and I am role-playing and I am being the shoe maker.

In every class the inspector went into there were different examples; it wasn't just a case of staff describing what they did, but the children were actually using the language. He was also given a sticker by one of the children and the child was able to explain why the inspector had merited this sticker. The Ofsted inspector's positive feedback was proof that the school was onto something exciting.

\section{Success Factors}

\section{A learning language and vocabulary.}

What seems to be important here is how the Language for Learning project provides a framework for all parties_-professionals, children, and parents - to talk about learning. In this way, learning takes centre-stage within the school community-a common language or framework for talking about learning and for making learning explicit. Although the language was made "childlike," it was relevant to everyone. It provides a way for children to respond, talk about what they are doing, and how they are learning, thereby enabling them to take a more proactive and participatory approach to their learning, supported by those who work with them. Even if children do not have the use of language, they are able to describe how they have been learning by identifying the appropriate animal. 


\section{A flexible design for professionals to use.}

One of the reasons for the success of this project seems to lie in it being a set of key ideas, yet flexible enough for professionals in different settings to design and implement, as evidenced by the extent to which it has become embedded within the school. This has only been possible by the school staff shaping its development and delivery. Rather than being something to be "fitted into" an already busy school schedule, it has become so much a part of the school's approach to learning that "it's just happening." It also proved to be the means by which staff could create a purposeful learning environment within the school.

\section{A fun way for children to talk about learning.}

The Language for Learning project provided children with a vocabulary with which to engage in their own learning. The animal imagery proved to be particularly appealing to children, and because of their familiarity with the imagery and its associated language the children were also able to draw on it and apply it in novel situations and contexts. Because the influence of the language extended beyond the nursery school to the home, it meant that parents/caregivers could feel part of their children's learning experience-and reinforce the learning language. Thus, the sustained involvement of children was central to the project.

\section{A positive experience about learning for parents.}

In contrast to the negative learning experiences of many of the parents involved, this approach proved to be a positive one, but only because school staff took the time and care to give the parents the support they needed. A variety of strategies were used to communicate this vocabulary of learning to parents/caregivers, and in time they too found the animal characters appealing and engaging. In the head teacher's view, the Language for Learning project was a really powerful way of engaging and empowering not only children but their parents too. She continued:

Many parents in this community feel that learning or school was done to them, it was something that was delivered and they were on the end of it and it didn't really mean very much. They got through it but they didn't actually aspire to be part of it or to take it anywhere, and once school was finished it was over. I think we have engaged parents at a different level.

Another reason for the success was the thoughtful way in which parents' involvement was managed, especially given the nature of the parents' own learning experiences at school. Overcoming the barriers created by such experiences played an important part in parents subsequently being able to articulate their hopes and aspirations for their children. The head teacher explained: 
For many parents the experience was very stressful as they were afraid of failing. They had negative associations with school from when they had been there and they brought these anxieties to the workshop. The teachers worked with the parents to build their confidence and reassure them that they could not fail. The atmosphere changed during the process and all of the parents commented at the end on what a positive experience it had been and that they had surprised themselves. Some even cried because they were so relieved that they had actually been able to do it; their level of self-esteem was so low. This huge learning curve for the parents highlighted to us the importance of including them in the projects. If our children were to learn they needed their parents learning alongside with them.

\section{A significant contribution to the wider community.}

The project was significant to the school and its community because the process of learning how to do something-and then actually applying those skills within a real setting-brought the whole thing to life. There was also considerable pride amongst the school staff, and the wider community, for what the children and the parents had done, and because of that the local young people have shown respect for the mural and it has not been vandalized.

\section{Conclusions}

If community-based research is collaborative, participatory, empowering, systematic, and transformative (Hills \& Mullett, 2000), then what happened in this nursery school community is a interesting example of what is possible. In terms of the principles on which such research proceeds, I suggest that:

\section{It created new knowledge upon which to base practice.}

An important factor in the engagement of both children and adults, and in enabling them to take responsibility for their own learning, was the use of imagery and metaphor. What seems to be important is the capacity of image and metaphor to communicate at a more fundamental level than words. The learning power animals-for example, the strategically aware wise owl-enable the individual to project particular qualities on to the owl, and then, when he or she is ready, to "own them" for him/herself. The animals also "de-centre" the teacher and carry a message of empowerment to the individual. 
It valued the work and perspectives of each participant.

A key aim of the project was to enable parents in the community to be more able to engage with learning for themselves, especially given that for many parents their own experiences of school and learning was disempowering. This meant that even the idea of participating in something like this was a considerable hurdle for many of them, to the point that some could not even walk through the doors of the school they went to. However, over time and with the support of the school staff, a remarkable change occurred. The parents gradually began to interact more confidently and became more aware of what they could achieve. The subsequent conversations they had about barriers to learn, together with their quotes about learning which were included in the booklet, could be viewed as significant steps in their own changing and learning.

\section{It dealt with a problem or practical issue which has been identified by the} community as being important to the life/health of that community.

The Language for Learning project challenges many of the key assumptions often made in relation to the achievement of white working class-children-especially in relation to the likely influence of previous generations on the experiences of children. It is obviously apparent that some of the young mothers who participated in the project and whose stories are included here did indeed feel marginalized from/through their educational experience and under-achieved at school. However, their narratives are evidence that the Language for Learning project offered parents a way of overcoming theses influences through a new understanding of learning and themselves. Indeed, the very process of designing the learning booklet proved to be almost a "therapeutic" way of working through their own beliefs about themselves and schools.

\section{It allowed people to develop new ways of thinking, behaving,}

\section{and practising.}

This project adds to what we know about the ecology of learning and transformation in the context of community. It links school-based "learning to learn" strategies to the re-engagement of parents with formal learning and to social transformation. It provides an in-depth understanding of how sophisticated ideas and opportunities around lifelong learning and empowerment can be communicated, and taken up, through metaphor and imagery.

\section{It made a lasting contribution to the community.}

What was striking about this project was how these ideas grew legs, walked into the local community, and had an impact on community learning and well-being. It enabled children, their parents and caregivers, and their community, to take responsibility for their own learning and change; and contributed to building and developing a stronger local community. 
Given what we know about cognitive, social, and emotional development in early childhood, and the important role of the home learning environment, this kind of strategy may well make a significant contribution in this area. This was a highly original social phenomenon and an outcome of an "engaged" research program and local school self-evaluation. Although only a small-scale inquiry, this initiative demonstrates in a powerful way that when the language of learning is made explicit and is consistently promoted by all members of a school community, it not only has a considerable effect within the school community, but also ripples out into the families and homes within the wider community too.

\section{Acknowledgments}

I am grateful to the head teacher, staff, children, and parents of the nursery school for their support with this research. I was impressed by their enthusiasm for the Language for Learning project, for the inspiring way in which they have worked with it, and for the time and energy they gave me when I was in the school.

\section{References}

Curtis, D. (2008). Ilminster Avenue Specialist Nursery School: Inspection Report. London: Ofsted.

de A'Echevarria, A. (2008). Success in teaching thinking programmes: 7 key classroom strategies. Learning and Teaching Retrieved from http://www.teachingexpertise.com/ebulletins/success-in-teaching-thinking-programmes-7-key-classroom-strategies-3180

Deakin Crick, R. (2006). Learning power in practice: A guide for teachers. London: Sage.

Deakin Crick, R., Broadfoot, P., \& Claxton, G. (2004). Developing an effective lifelong learning inventory: the ELLI project. Assessment in Education: Principles, Policy \& Practice, 11(3), 247-272. doi: 10.1080/0969594042000304582
Deakin Crick, R., \& Grushka, K. (2009). Signs, symbols and metaphor: linking self with text in inquiry-based learning. Curriculum Journal, 20(4), 447-464. doi: 10.1080/09585170903425069

Deakin Crick, R., McCombs, B., Haddon, A., Broadfoot, P., \& Tew, M. (2007). The ecology of learning: factors contributing to learner-centred classroom cultures. Research Papers in Education, 22(3), 267-307. doi: $10.1080 / 02671520701497555$

Deakin Crick, R., \& Wilson, K. (2005). Being a learner: a virtue for the 21st century. British Journal of Educational Studies, 53(3), 359-374.

Department for Education. (2013). Early Years Foundation Stage (EYFS). Retrieved from http://www.education.gov.uk/schools/ teachingandlearning/curriculum/a0068102/ early-years-foundation-stage-eyfs 
Feinstein, L. (2003). Very early evidence. CentrePiece 8(2), 24-30.

Goodman, A., \& Gregg, P. (2010). Poorer children's educational attainment: how important are attitudes and behaviour? York: Joseph Roundtree Foundation.

Goodman, A., Sibieta, L., \& Washbrook, E. (2009). Inequalities in educational outcomes among children aged 3 to 16. London: National Equality Panel.

Hills, M., \& Mullett, J. (2000). Community-based research: Creating evidence-based practice for health and social change. Paper presented at the Qualitative Evidence-based Practice Conference, Coventry University.
Hopkins, D. (2000). Powerful learning, powerful teaching and powerful schools. Journal of Educational Change, 1(2), 135-154.

Lakoff, G., \& Johnson, M. (2003). Metaphors we live by. Chicago: University of Chicago Press.

Watkins, C. (2001). Learning about Learning enhances Performance. Research Matters series no. 13. London: Institute of Education School Improvement Network

Watkins, C. (2006). When teachers reclaim learning. Forum, 48(2), 121-129.

Watkins, C., Carnell, E., Lodge, C., Wagner, P., \& Whalley, C. (2002). Effective learning. In F. McNeil (Ed.), Research Matters No 17. London: Institute for Education.

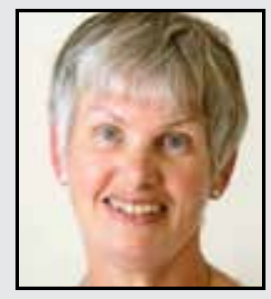

Helen Jelfs is a Visiting Fellow in the Graduate School of Education at the University of Bristol, UK. The focus of her research is the design and implementation of innovative pedagogies for student engagement in learning, such as deeper learning, learning how to learn, and authentic enquiry. She is interested in the stories young people tell about their learning experiences in school, particularly as they relate to the notions of "internal authority for learning" and "self-authorship." 